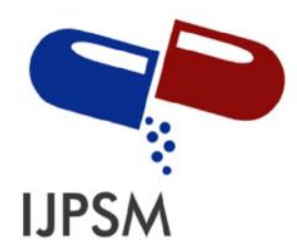

Yelti Mainita et al, Int. Journal of Pharmaceutical Sciences and Medicine (IJPSM),

Vol.6 Issue. 3, March- 2021, pg. 50-61

ISSN: 2519-9889

Impact Factor: 3.426

\title{
Overview of the Determination of Hydrochlorothiazide Levels in Pharmaceutical Preparations and Biological Matrices
}

\author{
Yelti Mainita $^{1}$; Harrizul Rivai ${ }^{2 *}$; Sastry Misfadhila ${ }^{1}$ \\ ${ }^{1}$ College of Pharmacy (STIFARM), Jl. Raya Siteba Kurao Pagang, Padang 25147, Indonesia \\ ${ }^{2}$ Faculty of Pharmacy, Andalas University, Limau Manih Campus, Padang 25163, Indonesia \\ *Email: harrizul@yahoo.co.id and harrizul@phar.unand.ac.id \\ DOI: 10.47760/ijpsm.2021.v06i03.005
}

\begin{abstract}
Hydrochlorothiazide (HCT) is a diuretic drug that works to inhibit sodium and chloride reabsorption. Therefore, the determination of hydrochlorothiazide levels is essential for quality control, whether as raw material, in pharmaceutical preparations, biological fluids, or mixtures. Search information on the determination of hydrochlorothiazide content was carried out through Google Scholar with the keywords "hydrochlorothiazide," "determination," "pharmaceutical preparation," "biological matrix," "mixture." The results showed that the levels of hydrochlorothiazide as a raw material could be determined by high-performance liquid chromatography (HPLC), capillary zone electrophoretic (CZE), micellar electrokinetic capillary chromatography (MEKC), capillary electrophoresis, chemiluminescence, voltammetry, and quantitative point tests. Hydrochlorothiazide in a pharmaceutical dosage form can be determined by high-performance liquid chromatography, spectrophotometric, electroanalytic, thin layer chromatography (TLC) methods, voltammetry, and capillary zone electrophoresis. Hydrochlorothiazide in urine is determined by electrochemical method, and hydrochlorothiazide in human blood plasma is determined by liquid chromatography method. In contrast, the hydrochlorothiazide in mixtures with other substances can be determined using voltammetric methods and high-performance liquid chromatography.
\end{abstract}

Keywords: Hydrochlorothiazides, assay, pharmaceutical preparations, biological matrices, mixtures

\section{Introduction}

Hydrochlorothiazide (HCT) is the most frequently prescribed antihypertensive drug worldwide. Over 97\% of all HCT prescriptions are 12.5 to $25 \mathrm{mg}$ per day. The antihypertensive efficacy of HCT with outpatient blood pressure monitoring is less clear than inpatients. The antihypertensive efficacy of hydrochlorothiazide (HCT) in daily doses of 12.5 to $25 \mathrm{mg}$ as measured in head-to-head studies with outpatient blood pressure measurements was consistently lower than all other drug classes. Because yield data at this dose are lacking, HCT is an unsuitable first-line drug for hypertension treatment [1].

Hydrochlorothiazide contains not less than $98.0 \%$ and not more than $102.0 \% \mathrm{C}_{7} \mathrm{H}_{8} \mathrm{ClN}_{3} \mathrm{O}_{4} \mathrm{~S}_{2}$ calculated against the dry matter. Hydrochlorothiazide is a white or almost white powder, odorless. Its melting temperature ranges from $201-204{ }^{\circ} \mathrm{C}$. Hydrochlorothiazide is soluble in sodium hydroxide, n-butylamine, and dimethylformamide; it is relatively difficult to dissolve in methanol; it is difficult to dissolve in water; 


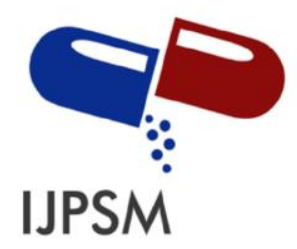

Yelti Mainita et al, Int. Journal of Pharmaceutical Sciences and Medicine (IJPSM), Vol.6 Issue. 3, March- 2021, pg. 50-61

ISSN: 2519-9889

Impact Factor: 3.426

insoluble in ether, chloroform, and dilute mineral acids. The chemical name for hydrochlorothiazide is 6Chloro-3,4-dihydro-2H-1,2,4-benzothiadiazole-7-sulfonamide 1,1-dioxide, molecular weight 297.74 and its structure, as shown in Figure 1 [2 ].<smiles>NS(=O)(=O)c1cc2c(cc1Cl)NCNS2(=O)=O</smiles>

Figure 1: Structure of the hydrochlorothiazide

\section{Method of collecting data}

In preparing this article, the technique used is literature study by searching for sources or literature in official books and national and international journals for the last 20 years (2000-2020). The keywords used for the data search were "hydrochlorothiazide, raw materials, pharmaceutical preparations, biological matrices, mixtures." This review article's primary reference search was carried out through trusted websites such as Science Direct, NCBI, ResearchGate, Google Scholar, and other published and trustworthy journals.

\section{Method of analysis of hydrochlorothiazide in pharmaceutical preparations 3.1 High-performance liquid chromatography (HPLC) method}

A high-performance liquid chromatography method was developed, validated, and applied to determine hydrochlorothiazide in human plasma. The effects of mobile phase composition, buffer concentration, mobile phase $\mathrm{pH}$ and organic modifiers on hydrochlorothiazide retention and internal standards were investigated. This method involved solid-phase extraction on the RP-select B cartridge followed by isocratic reverse phase chromatography on the Hibar Lichrospher 100 RP-8 column with UV detection at 230 nm. Recovery, selectivity, linearity, precision, and method accuracy were evaluated from spiny human plasma samples. The quantification limit is ten $\mathrm{ng} / \mathrm{mL}$. This method has been applied to monitor hydrochlorothiazide levels in patient samples [3].

High-performance liquid chromatography (HPLC) is method stability for hydrochlorothiazide. Hydrochlorothiazide was well separated from the degradation product using a reverse phase $(\mathrm{C}-18)$ column and a mobile phase consisting of Methanol: Buffer pH-3.2 (60:40 v/ v) and other HPLC parameters were flow rate of $1 \mathrm{~mL} / \mathrm{min}$, wavelength detection of $270 \mathrm{~nm}$ and injection volume of $20 \mu \mathrm{L}$. The method is validated for linearity, precision, accuracy, ruggedness, and durability. Results obtained after validation studies indicate that the single proposed method allows analysis of hydrochlorothiazide in the presence of degradation products formed under various stress conditions. The procedure developed is also applicable for determining hydrochlorothiazide's stability in commercial pharmaceutical dosage forms [8].

\subsection{Capillary zone electrophoretic (CZE) and micellar electrokinetic capillary chromatography (MEKC) methods}

Capillary zone electrophoretic (CZE) and micellar electrokinetic capillary chromatography (MEKC) methods were used to simultaneously separate hydrochlorothiazide and six angiotensin-II receptor antagonists (ARAIIs): candesartan, eprosartan mesylate, irbesartan, losartan potassium, telmisartan, and valsartan. The CZE and MEKC methods are suitable for the qualitative and quantitative determination of HCT / ARA-II combined in pharmaceutical formulations. Depending on ARA-II, at least one of two methods can be used for each combination. Both methods have been validated in terms of response linearity, reproducibility, and accuracy [4]. 


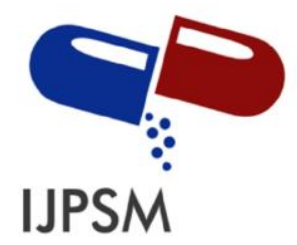

Yelti Mainita et al, Int. Journal of Pharmaceutical Sciences and Medicine (IJPSM), Vol.6 Issue. 3, March- 2021, pg. 50-61

ISSN: 2519-9889

Impact Factor: 3.426

\subsection{Capillary electrophoresis method}

The capillary electrophoresis method was developed for the simultaneous determination of hydrochlorothiazide and several angiotensin-converting enzyme (ACE) inhibitors: enalapril, lisinopril, quinapril, fosinopril, ramipril, and cilazapril. The most critical parameter is the $\mathrm{pH}$ of the buffer that is running. The separation was carried out on fused silica capillaries (total length $52 \mathrm{~cm}$ x $75 \mu \mathrm{m}$ ID) using sodium phosphate buffer (pH 7.25; $100 \mathrm{mM}$ ). This method is successfully applied to the quantitative determination of this compound in a suitable pharmaceutical formulation. This method was validated in terms of response linearity, reproducibility, and accuracy [5].

\subsection{Chemiluminescence Method}

A new chemiluminescence method for the determination of hydrochlorothiazide (HCT) has been developed based on the reaction between $\mathrm{Ce}$ (IV) in an acidic medium and this diuretic agent in the presence of rhodamine $6 \mathrm{G}$ as a sensitizer. The method described is based on recording the entire chemiluminescence intensity-versus-time profile, allowing other measured parameters such as total area proportional to the analyte concentration. The optimal chemical conditions for chemiluminescence emissions were investigated. Two defining approaches, intensity, and area, have been proposed. Linear calibration graph for the concentration range from 0.5 to $30 \mu \mathrm{g} / \mathrm{mL}$. The detection limits were 0.34 and $0.16 \mu \mathrm{g} / \mathrm{mL}$ for intensity and area measurements, respectively. For the analysis of 7.5 and $20 \mu \mathrm{g} / \mathrm{mL} \mathrm{HCT}$, the relative error is less than $2 \%$ if the error propagation theory is assumed. This chemiluminescence procedure is applied to determine HCT in pharmaceutical formulations, with excellent recovery, because the determination is free from interference from common excipients and other drugs also present in the formulation [7].

\subsection{Partial least squares method}

This work develops and validates a new multivariate diffuse reflecting method near-infrared for the direct determination of hydrochlorothiazides in pharmaceutical powder samples. The best partial least squares (PLS) models were obtained in the spectral region from 1640 to $1780 \mathrm{~nm}$, with centered-averaged data pre-processed by the first derivative and Savitzky-Golay refinement followed by vector normalization. This model was built with four latent variables and gave the root mean square prediction error of $1.7 \%$. This method is validated according to the appropriate regulations in the range of 21.25 to $29.00 \mathrm{mg}$ of hydrochlorothiazide per $150 \mathrm{mg}$ of powder (average mass tablet), with an estimated number of benefits, such as accuracy, precision, linearity, analytical sensitivity, detectability, bias, and residual prediction deviation (RPD). The net analyte signal (NAS) concept was used to estimate multiple benefits figures and plot pseudo-univariate calibration curves. According to the official high-performance liquid chromatography (HPLC) method, tablets' determination is manufactured in powder form. Finally, the extrapolated method for determining whole tablets gave a prediction error of less than $\pm 9 \%$. The developed method provides the advantage of about fifteen times faster than the reference HPLC method [14].

\subsection{Method of anodic stripping voltammetry and cyclic voltammetry}

The electrochemical oxidation behavior of hydrochlorothiazide (HCT) on glass carbon as a working electrode was investigated in the Britton-Robinson (B-R) pH 3 buffer, using anodic stripping voltammetry (ASV) and cyclic voltammetry $(\mathrm{CV})$. This drug provides a clear voltammetric oxidation peak at $+1200 \mathrm{mV}$ versus the $\mathrm{Ag}$ / $\mathrm{AgCl}$ reference electrode. The electrochemical oxidation process proved to be irreversible and diffusion controlled, with adsorption characteristics over the entire $\mathrm{pH}$ range. Optimized conditions, such as time and accumulation potential, scan rate, frequency, pulse amplitude, working electrode variation, and instrument parameters are studied. The calibration graph for HCT was obtained from $4 \times 10-6$ to $4 \times 10-5 \mathrm{M}$ (correlation coefficient $=0.997)$ using the developed electroanalytic method (ASV). The detection limit for this drug is 4.3 $\times 10-9 \mathrm{M}$. ASV, and CV techniques with sufficient precision and accuracy have been developed and applied for the direct determination of HCT in commercial tablets without separation or extraction procedures and biological fluids such as urine and plasma [9]. 


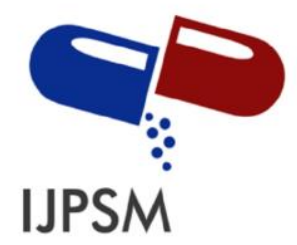

Yelti Mainita et al, Int. Journal of Pharmaceutical Sciences and Medicine (IJPSM), Vol.6 Issue. 3, March- 2021, pg. 50-61

ISSN: 2519-9889

Impact Factor: 3.426

The electrochemical preparation and characterization of nickel hydroxide-modified electrodes and their behavior as an electrocatalyst against hydrochlorothiazide oxidation (HCTZ) were investigated. The electrochemical behavior of the modified electrodes and the electrooxidation of HCTZ were explored using cyclic voltammetry. The modified electrode's voltammetric response in detecting HCTZ is based on the electrochemical oxidation of Ni (II) / Ni (III) and chemical redox processes. Analytical parameters for the electrooxidation of HCTZ by nickel hydroxide modified nickel electrodes were obtained in $\mathrm{NaOH}$ solution, where the linear voltammetry response was in the concentration range from $1.39 \times 10^{-5}$ to $1.67 \times 10^{-4} \mathrm{~mol} / \mathrm{L}$ with a detection limit of $7,92 \times 10^{-6} \mathrm{~mol} / \mathrm{L}$ and a sensitivity of $0.138 \mu \mathrm{A} \mathrm{L} / \mathrm{mmol}$. This analysis was used to explain the kinetics and oxidation mechanism of HCTZ with a modified electrode [11].

\subsection{Quantitative point test analysis}

The method of quantitative point test analysis for hydrochlorothiazide used diffuse reflectance spectroscopy. Reflectance measurements were carried out by analyzing colored compounds $(\lambda=585 \mathrm{~nm})$ resulting from hydrochlorothiazide and p-dimethylaminocinnamaldehyde (PDAC) in an acidic medium. This reaction occurs on the filter paper after heating to $80^{\circ} \mathrm{C}$ for 8 minutes. The factorial design allows for multiple reaction factors simultaneously to obtain the best reaction conditions. These factors include heating temperature, heating time, acid volume, and PDAC volume. Linearity was studied in the range $3.36 \times 10^{-2}$ to $1.01 \times 10^{-1} \mathrm{~mol} / \mathrm{L}$ with a correlation coefficient of 0.998 . The detection limit is estimated at $1.32 \times 10^{-2} \mathrm{~mol} / \mathrm{L}$. Commercial samples were analyzed using the proposed method, and the results were better than those of the United States Pharmacopoeia, which suggests that quantitative point test analysis with diffuse reflectance can be used successfully to determine hydrochlorothiazide in drugs [10].

\subsection{Differential pulse voltammetry (DPV) method}

Carbon nanotube/silicon rubber multiwall composite electrodes (MWCNT/SR) have been used for the determination of hydrochlorothiazide (HCTZ) in pharmaceutical formulations by differential pulse voltammetry (DPV). The electrooxidation process was evaluated by cyclic voltammetry. It was observed that the HCTZ presented an irreversible oxidation peak at $0.82 \mathrm{~V}$ vs. the saturated calomel electrode (SCE) in the potential range 0.5 to $1.1 \mathrm{~V}$, in the Britton-Robinson $\mathrm{pH}$ buffer of 7.0 at MWCNT/SR. HCTZ was determined by DPV using composite electrode MWCNT/SR 70\% (MWCNT, m/m) after optimizing experimental parameters. The linear range was from 5.0 to $70.0 \mu \mathrm{mol} / \mathrm{L}$, with a detection limit (LOD) of $2.6 \mu \mathrm{mol} / \mathrm{L}$. According to Student's t-test, the HCTZ was determined in a pharmaceutical formulation using the proposed composite electrode, and the results were approved by the liquid chromatography high performance (HPLC) official method within a $95 \%$ confidence level t-test [13].

\section{Method of analysis of hydrochlorothiazide in mixtures 4.1 Mixture of hydrochlorothiazide and enalapril}

A high-performance liquid chromatography procedure is presented to determine hydrochlorothiazide (HCT) and enalapril maleate (EM) in pharmaceutical tablets. An aliquot of the sample was dissolved in $15 \%$ acetonitrile $(\mathrm{ACN})$ containing theophylline as internal standard and chromatographed on the Supelcosil LC-8 column $(5 \mathrm{~m} \mu),(150 \mathrm{~mm} \times 4.6 \mathrm{~mm}$ i.d.). The mobile phase is $3.0 \mathrm{mM}$ tetrabutylammonium hydrogen sulfate (TBAHS) in ACN/water/triethylamine (TEA), (14, 85.6, $6.4 \mathrm{~V} / \mathrm{V})$ adjusted to $\mathrm{pH} 4.1$ by glacial acetic acid. Detection was at $220 \mathrm{~nm}$. The method was tested for linearity, accuracy, recovery, and specificity [14].

\subsection{Mixture of hydrochlorothiazide and spironolactone}

Hydrochlorothiazide (HCT) and spironolactone (SPR) are primarily formulated in antihypertensive formulations. Several methods have been developed and validated for their determination; these methods include spectrophotometric and chemometric-assisted spectrophotometry. The spectrophotometric methods developed are the isosbestic point method (ISO) and the ratio reduction method (RS). The absorbance values at $232.4\left(\lambda_{\text {iso } 1}\right)$ and $257.6 \mathrm{~nm}\left(\lambda_{\text {iso2 }}\right)$ were used to determine the total mixture concentration, whereas HCT could be directly determined at $317.2 \mathrm{~nm}\left(\lambda_{\max }\right)$ and a reduced SPR concentration could be obtained. Also, the SPR 


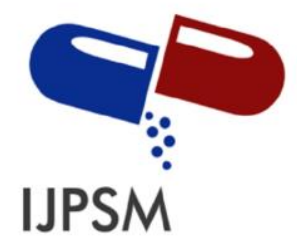

Yelti Mainita et al, Int. Journal of Pharmaceutical Sciences and Medicine (IJPSM), Vol.6 Issue. 3, March- 2021, pg. 50-61

ISSN: 2519-9889

Impact Factor: 3.426

concentration can be calculated by the RS method using absorbance at $243.8 \mathrm{~nm}\left(\lambda_{\max }\right)$. A wavelength selection method based on genetic algorithms (GAs) was developed and compared with the conventional partial least squares (PLS) method. In this method, several parameters are adjusted, and the optimal parameter settings are determined using an experimental design. The chemometric method developed has been successfully applied to determine HCT and SPR and determine impurity and degradation products. The proposed method was successfully applied to determine HCT and SPR in commercial tablets and statistically compared with each other and with the methods reported. No significant differences were found, giving accuracy and precision [15].

Methods for determining hydrochlorothiazide (HCT) and spironolactone (SPR) in their mixtures and the presence of impurities or their degradation products have been developed. The first method is based on thinlayer chromatography (TLC) combined with the discrete freckles' densitometric determination. The separation was achieved using TLC plates of silica gel 60 F254 and ethyl acetic acid-chloroform-formate-triethyl amine (7: 3: 0.1: 0.1, volume) as the expanding system. Good correlations were obtained between the studied drug's integrated peak area and the corresponding concentrations in different ranges. The second method is based on high-performance liquid chromatography with ultraviolet detection, in which the proposed components are separated on a reverse-phase C18 analytical column using a gradient elution system with deionized wateracetonitrile (97: 3, v / v) for $8 \mathrm{~min}$. Then acetonitrile was increased successively to $35 \%$ in the next 2 minutes and kept constant in the next 10 minutes. Finally, 3\% acetonitrile was recovered to stabilize the chromatography system. The flow rate was maintained at $2 \mathrm{~mL} / \mathrm{min}$ and the detection wavelength at $230 \mathrm{~nm}$. Linear regression was obtained in the range of $4.0-50 \mu \mathrm{g} / \mathrm{mL}$ and $5.0-50 \mu \mathrm{g} / \mathrm{mL}$ for HCT and SPR, respectively. Different parameters affecting the suggested method are optimized for maximum separation of the quoted components. The system suitability parameters of the two methods developed were also tested. According to ICH guidelines, the suggested methods were validated and were successfully applied to determine HCT and SPR in their commercial tablets. The two methods were also statistically compared and reported without any significant difference in performance [20].

\subsection{Mixture of hydrochlorothiazide and triamteren}

Hemodialysis is the most commonly used method for the treatment of chronic kidney disease. In this procedure, some patients use diuretics to control weight gain and blood pressure. In this work, a voltammetric sensor based on a glassy carbon electrode modified with carbon nanotubes (GCE/MWCNT) is described for the simultaneous determination of hydrochlorothiazide (HCT) and triamterene (TRT) diuretics. Diuretic oxidation on the GCE/MWCNT surface was observed at 1.01 and $1.17 \mathrm{~V}$ for HCT and TRT, respectively, allowing simultaneous determinations, which were not possible with unmodified glass carbon electrodes. The GCE/MWCNT electrodes provide a 6-fold and 10-fold gain in anode peak intensity for HCT and TRT, respectively, compared to the unmodified electrodes. After optimizing the conditions $(\mathrm{pH}$, accumulation time, and accumulation potential), analytical curves are generated for the analyte range from $1.0 \times 10^{-7}$ to $2.0 \times 10^{-5}$ mol/L. The detection limits for HCT and TRT are $2.8 \times 10^{-8}$ and $2.9 \times 10^{-8} \mathrm{~mol} / \mathrm{L}$. A high-performance liquid chromatography method with diode array detection was also developed to determine HCT and TRT in hemodialysis samples compared to electroanalytic methods [16].

\subsection{Mixture of hydrochlorothiazide and benazepril hydrochloride}

Partial least squares regression (PLSR) and support vector regression (SVR) are two popular chemometric models subjected to comparative studies in the presented work. The comparison shows their characteristics through their application to analyze Hydrochlorothiazide (HCZ) and Benazepril hydrochloride (BZ) in the presence of HCZ impurities; Chlorothiazide (CT) and Salamide (DSA) as case studies. The analysis results proved valid for analyzing two active ingredients in raw materials and pharmaceutical dosage forms by handling UV spectral data in the range (220-350 nm). For precise analysis, the 4-factor 4-stage set experimental design resulted in a training set consisting of 16 mixtures containing different disturbing species ratios. A set of independent tests consisting of 8 mixtures was used to validate the suggested model's predictive ability. The results presented indicate the ability of the multivariate calibration model to analyze $\mathrm{HCZ}$ and BZ 


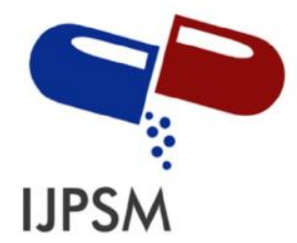

Yelti Mainita et al, Int. Journal of Pharmaceutical Sciences and Medicine (IJPSM), Vol.6 Issue. 3, March- 2021, pg. 50-61

ISSN: 2519-9889

Impact Factor: 3.426

in the presence of HCZ CT and DSA impurities with high selectivity and average percentage gain accuracy $(101.01 \pm 0.80)$ and $(100.01 \pm 0.87)$ for $\mathrm{HCZ}$ and BZ using the PLSR model, respectively and $(99.78 \pm 0.80)$ and $(99.85 \pm 1.08)$ for $\mathrm{HCZ}$ and BZ using the SVR model, respectively. The dosage form analysis results were statistically compared with the reference HPLC method without significant accuracy and preciseness. The SVR model provides more accurate results than the PLSR model and shows high generalizability. However, PLSR still has the advantage of being fast in optimization and implementation [17].

\subsection{Mixture of hydrochlorothiazide and telmisartan}

Simple, sensitive, specific, and economical spectrophotometric methods were developed and validated simultaneously to estimate Hydrochlorothiazide and Telmisartan in the tablet dosage form. New methods based on the simultaneous estimation of drugs in binary mixtures without separation were previously developed. In the multiple wavelength method, Hydrochlorothiazide and Telmisartan are measured on the principle that the absorbance differing between two points on the spectrum of the mixture is directly proportional to the interest component's concentration is independent of component interference. Recovery studies statistically validated the accuracy and reproducibility of the proposed method. This method allows the simple, fast, and direct determination of Hydrochlorothiazide and Telmisartan in commercially available tablet dosage forms without prior separation and, therefore, can be used for routine analysis of both drugs in a quality control laboratory [18].

A simple, sensitive, specific, and economical spectrophotometric method was developed and validated for Hydrochlorothiazide and Telmisartan's simultaneous calculation in the tablet dosage form. New methods based on the simultaneous estimation of drugs in binary mixtures without prior separation were developed. In the simultaneous equation method, Hydrochlorothiazide and Telmisartan were measured using the absorptivity value at the selected wavelength, namely, $273 \mathrm{~nm}$ and $295 \mathrm{~nm}$, respectively. Recovery studies statistically validated the accuracy and reproducibility of the proposed method. The simultaneous equation method allows simple, fast, and direct determination of Hydrochlorothiazide and Telmisartan in commercially available tablet dosage forms without prior separation and can therefore be used for routine analysis of both drugs in a quality control laboratory [19].

\subsection{Mixture of hydrochlorothiazide and valsartan}

This work deals with the simultaneous determination of hydrochlorothiazide (HCTZ) and valsartan (VAL) by square wave voltammetry using cathodically doped diamond electrodes. This method demonstrated a linear response to HCTZ and VAL in the concentration range of 1.97-88.1 $\mu \mathrm{mol} / \mathrm{L}$ and $9.88-220 \mu \mathrm{mol} / \mathrm{L}$, respectively, in a Britton-Robinson buffer solution $(\mathrm{pH} 5.0)$, with detection limits of $0.639 \mu \mathrm{mol} / \mathrm{L}$ and 0.935 $\mu \mathrm{mol} / \mathrm{L}$, respectively. The proposed method was successfully applied in the two antihypertensives' simultaneous determination in the combined dosage form, and the results were obtained using the highperformance liquid chromatography method [21].

\subsection{Mixture of hydrochlorothiazide and losartan potassium}

A combination of multi-syringe chromatographic analytical techniques with extraction disc sorbents for the pre-concentration and determination of hydrochlorothiazide and losartan potassium in shallow, groundwater, and outlet wastewater samples has been developed. The developed system has been proven to determine hydrochlorothiazide and losartan potassium in spiked water samples with yields ranging from 95 to $118 \%$. This method involves online enrichment of the target analyte from a spiked water sample onto a Cation-SR absorbent material. The analyte is then eluted and transported to the monolithic column, RP-18e Chromolith Flash column $(25 \mathrm{~mm} \times 4.6 \mathrm{~mm}$ i.d.). The mobile phase used was $10 \mathrm{mM}$ potassium dihydrogen phosphate $(\mathrm{pH} 3.0)$ : acetonitrile: methanol $(60: 30: 10 \mathrm{v} / \mathrm{v} / \mathrm{v})$, flow rate $0.8 \mathrm{~mL} / \mathrm{minutes}$. UV detection was carried out at $226 \mathrm{~nm}$. Under optimized chemical and physical variables, the detection limits for hydrochlorothiazide and losartan potassium calculated as 3Syx/w were 0.07 and $0.09 \mathrm{mg} / \mathrm{L}$, respectively, for a sample loading volume $1.0 \mathrm{~mL}[23]$. 


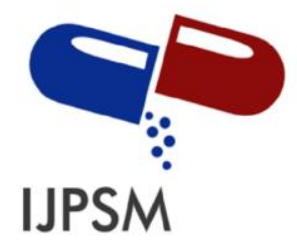

Yelti Mainita et al, Int. Journal of Pharmaceutical Sciences and Medicine (IJPSM), Vol.6 Issue. 3, March- 2021, pg. 50-61

ISSN: 2519-9889

Impact Factor: 3.426

A new, precise, accurate gradient back phase high-performance liquid chromatography (RP-HPLC) method has been developed for the simultaneous determination of Hydrochlorothiazide (HCT) and Losartan potassium (LOS) in tablets. The stationary phase is the Microbondapak C18 column $(10 \mu, 300 \mathrm{~mm} \times 3.9 \mathrm{~mm}$ ID). Gradient elution with a mobile phase of aqueous methanol $(\mathrm{pH}=3)$ was used for separation. Detection was carried out at $270 \mathrm{~nm}$ using a UV detector. The flow rate was $1.0 \mathrm{~mL} / \mathrm{minute}$ and the retention times were 7.89 minutes and 15.15 minutes for HCT and LOS, respectively. Linearity was obtained in a concentration range of $0.5-200 \mu \mathrm{g} / \mathrm{mL}$ for HCT and $2-800 \mu \mathrm{g} / \mathrm{mL}$ for LOS. The mean recovery percentages were $100.29 \%$ and $99.16 \%$ for HCT and LOS [24].

Simultaneous determination of hydrochlorothiazide (HCTZ) and losartan (LOS) in a pharmaceutical formulation using differential pulse voltammetry (DPV) was developed. Two magnificent reproducible peaks of HCTZ and LOS oxidation, with a separation of $0.23 \mathrm{~V}$, were obtained in the Britton-Robinson (BR) buffer $(\mathrm{pH} 9.5)$ using an anodically treated boron-treated diamond electrode. Under optimal analytical, experimental conditions, the voltammetric method shows a linear response for the simultaneous determination of HCTZ and LOS in the concentration range of $3.0 \times 10^{-6}$ to $7.4 \times 10^{-5} \mathrm{~mol} / \mathrm{L}$ for both compounds, with a detection limit of 1.2. $\times 10^{-6} \mathrm{~mol} / \mathrm{L}$ and $9,5 \times 10^{-7} \mathrm{~mol} / \mathrm{L}$, respectively. The proposed method was successfully applied in the simultaneous determination of LOS and HCTZ content in pharmaceutical formulations, the accuracy of which was evidenced by the excellent compatibility of the results (paired t-test at $95 \%$ confidence level) with those obtained using high-performance liquid chromatography (HPLC) [28].

\subsection{Mixture of hydrochlorothiazide and rutin}

Capillary zone electrophoresis by amperometric detection (CZE-AD) was first applied to the simultaneous determination of rutin (RT) and hydrochlorothiazide (HCT) in compound Chinese herbal medicines and human urine samples. Both analytes can be analyzed entirely within 12 minutes and show a significant current carbon electrode response under optimal conditions. It is known that the linear range of HCT is from $2.0 \times 10^{-6}$ to 1.0 $\times 10^{-4} \mathrm{~mol} / \mathrm{L}$, and RT is from $1.0 \times 10^{-6}$ to $1.0 \times 10^{-4} \mathrm{~mol} / \mathrm{L}$. The sensitivity is determined by linear regression and calculated $-7.02 \times 10^{4}$ and $2.17 \times 10^{5} \mathrm{nA} \mathrm{L} / \mathrm{mol}$, respectively, and the detection limits are $5.0 \times 10^{-7}$ and $2.0 \times 10^{-7} \mathrm{~mol} / \mathrm{L}$, respectively $(\mathrm{S} / \mathrm{N}=3)$. The above results indicate that this method has high sensitivity, good repeatability, high selectivity and can be used to study drug metabolic kinetics. Excellent results were obtained when this method was used to simultaneously analyze the amounts of RT and HCT in one common compound of Chinese herbal medicine - Zhen Ju Jiang Ya Pian and human urine samples [25].

\subsection{Mixture of hydrochlorothiazide and irbesartan}

Three new analytical methods have conducted simultaneous determination of hydrochlorothiazide and irbesartan in binary mixtures without prior separation. The first method is presented for the spectrophotometric determination of the derivative of a binary mixture with overlapping spectra based on the compensation technique. The exact contribution of one of the components in a binary mixture can be measured and the amount quantified. The second method uses the first derivative of the radio spectrum. The ratio spectrum is obtained by dividing the absorption spectrum of a binary mixture using its components. Amplitudes in the first derivative of the ratio spectrum at 231, 266, 279, 238, and $248 \mathrm{~nm}$ were chosen to determine the hydrochlorothiazide and irbesartan in the binary mixture. The other components' concentrations were then determined from the respective calibration charts, which were treated similarly. With the third method, the absorbance ratio method, the determination of hydrochlorothiazide and irbesartan was carried out using absorbance readings at $272 \mathrm{~nm}, 241 \mathrm{~nm}$, and $263 \mathrm{~nm}$ in the zero-order spectrum of the mixture. The absorbance ratio was also developed as a method of comparison. All three methods are simple, accurate, fast, and do not require an initial separation step and, therefore, can be used for routine analysis of both drugs in a quality control laboratory [26].

\subsection{Mixture of hydrochlorothiazide and medoxomil olmesartan}

A simple, specific, accurate, precise, and reproducible method has been developed and validated for the simultaneous estimation of hydrochlorothiazide and medoxomil olmesartan in the combined dosage form by 


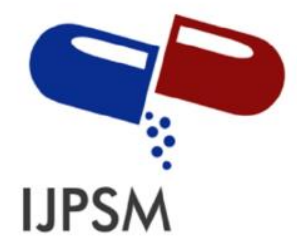

Yelti Mainita et al, Int. Journal of Pharmaceutical Sciences and Medicine (IJPSM), Vol.6 Issue. 3, March- 2021, pg. 50-61

ISSN: 2519-9889

Impact Factor: 3.426

the UV spectrophotometric method. The UV spectrophotometric method includes the simultaneous equation method (Method I) $271.5 \mathrm{~nm}$ and $257.0 \mathrm{~nm} \lambda_{\max }$ of the two drugs selected, the absorbance ratio method (Method II) $261.5 \mathrm{~nm}$, isoabsorptive wavelength, and $257.0 \mathrm{~nm}$ were selected for estimation. hydrochlorothiazide and olmesartan medoxomil respectively. In the three-wavelength method (Method III), the two wavelengths are chosen such that the hydrochlorothiazide provides the same absorbance (263.8 and 278.4 $\mathrm{nm})$ at the two selected wavelengths while the third wavelength $(316.5 \mathrm{~nm})$ is such that olmesartan provides almost zero absorbance. Both drugs follow Beer's law in a concentration range of $5-25 \mu \mathrm{g} / \mathrm{mL}$. The \% recovery for both drugs was almost $100 \%$ representing the accuracy of the proposed method. According to the ICH guidelines, the proposed method's validation was carried out for accuracy, precision, specificity, and ruggedness. The proposed method can be successfully applied in routine work to determine hydrochlorothiazide and medoximil olmesartan in combined dosage forms [27].

\section{Analysis of hydrochlorothiazide in biological matrices}

\subsection{Mixture of hydrochlorothiazide and folic acid in biological samples}

Carbon paste electrode-based (CPE) sensors modified with benzoylferocene (BF) and NiO nanoparticles (NiO/NPs) are used for highly sensitive voltammetry and electro-catalytic measurements of hydrochlorothiazide (HCT) and folic acid (FA). The NiO/NP was synthesized via direct chemical deposition methods and characterized by X-ray diffraction (XRD) and scanning electron microscopy (SEM) techniques. Thus, the sensor represents an appropriate and robust electron-intermediate behavior and the oxidation peaks of HCT and FA, which are very well separated. The peak current is obtained from squared. The wave voltammetry technique (SWV) was linearly dependent on HCT and FA concentrations in the range 1.0-500.0 and 50.0-500.0 $\mu \mathrm{mo} / \mathrm{L}$ with detection limits of 0.14 and $4.3 \mu \mathrm{mo} / \mathrm{L}$, respectively. These mediator/nanoparticles modified electrodes are applied to detect and measure HCT and FA in pharmaceutical and biological samples [29].

\subsection{Determination of hydrochlorothiazide in a urine sample}

This work describes the development, optimization, and validation of an electrochemical method to determine hydrochlorothiazide (HCTZ) in the urine. This method allows the fast, inexpensive, and reliable determination of the current administration of diuretics used in doping control in sports. The sensor response is determined by differential pulse voltammetry (DPV). The glass carbon electrode has been modified with multiwall carbon nanotubes (MWCNT) and gold nanoparticles. The sensors are calibrated in a sample analyzed matrix by the cumulative standard summation method. Method validation is based on bottom-up evaluation Measurement uncertainty is a component combined using the Monte Carlo Method (MCM). It applies without limitation regarding the value of the component's uncertainty and the measurement function's linearity. The developed metrological model is implemented in an MS-Excel spreadsheet. The measurements' electrochemical adequacy was assessed by comparing their relative standard uncertainty with a target value of $20 \%$ and by evaluating the suitability of the measurements with the determinations made with the reference procedure. The tools developed for the construction and optimization of functioning electrodes can be applied to other analytes and matrices measurements. The standard cumulative summation method used and each measurement uncertainty model can be applied to any non-destructive chemical measurement of solutions. [30]

\subsection{Determination of hydrochlorothiazide in human plasma}

A fast and sensitive liquid chromatography/tandem mass spectrometry for hydrochlorothiazide determination in human plasma has been developed and validated. The analyte and irbesartan, used as internal standards, are precipitated and extracted from plasma using methanol. The analysis was carried out on the Phenomenex Kromasil C8 column with water and methanol (27:73, v/v) as the mobile phase. Linearity used to be assessed from 0.78 to $200 \mathrm{ng} / \mathrm{mL}$ in plasma. The analytical method proved to be applicable in pharmacokinetics after oral administration of $12 \mathrm{mg}$ hydrochlorothiazide tablet to 20 healthy volunteers [6].

The sensitive, selective, and fast liquid chromatography/mass spectrometry method (LC-MS/MS) was developed and validated to determine hydrochlorothiazide (HCTZ) in human plasma. Plasma samples were 


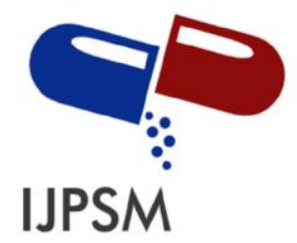

Yelti Mainita et al, Int. Journal of Pharmaceutical Sciences and Medicine (IJPSM), Vol.6 Issue. 3, March- 2021, pg. 50-61

ISSN: 2519-9889

Impact Factor: 3.426

prepared by solid-phase extraction using an Oasis HLB cartridge $30 \mathrm{mg} / 1 \mathrm{CC}$. Chromatographic separation was performed on a Thermo Hypurity Advance column ( $50 \mathrm{~mm}$ x $4.6 \mathrm{~mm}$ i.d., $5 \mu \mathrm{m})$. The mobile phase consisted of HPLC grade acetonitrile: $2 \mathrm{mM}$ ammonium acetate $(90: 10 \mathrm{v} / \mathrm{v})$ with a $0.5 \mathrm{~mL} / \mathrm{min}$ flow rate. Detection of internal standard hydrochlorothiazides and zidovudine (IS) was achieved by electrospray ionization (ESI) MS/MS in negative ion mode. The total run time of chromatography was 2.5 minutes. The linear range of this method is from 2,036-203,621 ng/mL. The mass transition ion pairs are followed as $\mathrm{m} / \mathrm{z} 296.10 / 205.00$ for HCTZ and $\mathrm{m} / \mathrm{z} 266.10 / 223.10$ for zidovudine. The mean overall recovery for HCTZ was $66.40 \%$, with a precision of $2.44 \%$. The mean internal standard recovery (AZT) was $63.62 \%$, with a precision ranging from $2.06 \%$ to $5.40 \%$. This method was successfully applied to the pharmacokinetic evaluation of hydrochlorothiazide after a single oral dose of $25 \mathrm{mg}$ hydrochlorothiazide in healthy volunteers [12].

The rapid and sensitive liquid chromatography-tandem mass spectrometry (LC-MS/MS) method has been developed and validated for the simultaneous estimation of hydrochlorothiazide, quinapril, and their quinaprylate metabolites in human plasma. After solid-phase extraction (SPE), the analyte and IS were chromatographed on a hypurity C8 column (100 mm x $2.1 \mathrm{~mm}$ i.d., particle size $5 \mu \mathrm{m})$ using an injection volume of $2 \mu \mathrm{L}$ with a run time of 2.8 minutes. An isocratic mobile phase consisting of $0.5 \%(\mathrm{v} / \mathrm{v})$ formic acid: acetonitrile $(25: 75, \mathrm{v} / \mathrm{v})$ was used to separate these drugs. This medicinal product's precursors and ions are monitored on a triple quadrupole mass spectrometer, operating in dual reaction monitoring (MRM) mode without a polarity switch. The proposed method is validated in the range 5-500 $\mathrm{ng} / \mathrm{mL}$ for the hydrochlorothiazide method and 5-1500 $\mathrm{ng} / \mathrm{mL}$ for quinapril and quinaprylate. Inter-batch and intra-batch precision (coefficient of variation $-\% \mathrm{CV}$ ) across the five validations runs a lower quantitative limit (LLOQ), lower quality control (LQC), intermediate quality control (QMC), higher quality control (HQC), and the upper quantitation limit (ULOQ) is less than 15. The accuracy specified at this level is within $\pm 13 \%$ in terms of relative error percentage [22].

In this study, a rapid and sensitive liquid chromatography/tandem mass spectrometry method for determining hydrochlorothiazide in humans plasma is developed and validated. The analyte and irbesartan, used as internal standards, are precipitated and extracted from plasma using methanol. The analysis was carried out on the Phenomenex Kromasil C8 column with water and methanol $(27: 73, \mathrm{v} / \mathrm{v})$ as the mobile phase. Linearity used to be assessed from 0.78 to $200 \mathrm{ng} / \mathrm{mL}$ in plasma. The analytical method proved to be applicable in pharmacokinetics after oral administration of $12 \mathrm{mg}$ hydrochlorothiazide tablet to 20 healthy volunteers [31].

A specific, sensitive and rapid method based on high-performance liquid chromatography combined with tandem mass spectrometry (HPLC-MS/MS) was developed for the simultaneous determination of olmesartan (OLM) and hydrochlorothiazide (HCTZ) in human plasma and urine. Solid-phase extraction (SPE) was used to isolate the analyte from the biological matrix, followed by injecting the extract into column $\mathrm{C} 18$ by isocratic elution. The detection was carried out on a triple quadrupole tandem mass spectrometer in dual reaction monitoring (MRM) mode using negative electrospray ionization (ESI). Methods are validated in a concentration range of $1.00-1000 \mathrm{ng} / \mathrm{mL}$ and $5.00-5000 \mathrm{ng} / \mathrm{mL}$ for OLM in humans plasma and urine and $0.500-200 \mathrm{ng} / \mathrm{mL}$ and $25.0-25,000 \mathrm{ng} / \mathrm{mL}$ for HCTZ in human plasma and urine, respectively. The precision of inter-and intra-run OLM and HCTZ is less than 15\%, and accuracy is within $85-115 \%$ for plasma and urine. The mean extraction recoveries were $96.6 \%$ and $92.7 \%$ for OLM, $87.2 \%$, and $72.1 \%$ for HCTZ in human plasma and urine. Linearity, recovery, matrix effects, and stability were validated for OLM/HCTZ in human plasma and urine [32].

A rapid and sensitive liquid chromatography-tandem mass spectrometry method (LC-MS/MS) was developed and validated for the simultaneous estimation of hydrochlorothiazide, quinapril, and quinapril metabolites in human plasma. After solid-phase extraction (SPE), analyte and IS were taken chromatographically on a hypurity $\mathrm{C} 8$ column $(100 \mathrm{~mm} \times 2.1 \mathrm{~mm}$ i.d., particle size $5 \mu \mathrm{m})$ using a two $\mu \mathrm{L}$ volume injection with a run time of 2.8 minutes. The isocratic mobile phase consisting of $0.5 \%(\mathrm{v} / \mathrm{v})$ formic acid: acetonitrile $(25: 75, \mathrm{v} / \mathrm{v})$ was used to separate all of these drugs. This drug's precursors and productions are monitored with a threequadrupole mass spectrometer, operating in a dual reaction monitoring mode (MRM) without a polarity switch. The proposed method is validated over the range from $5-500 \mathrm{ng} / \mathrm{mL}$ for the hydrochlorothiazide method and $5-1500 \mathrm{ng} / \mathrm{mL}$ for quinapril and quinaprilate. Interbatch and intra-batch precision (coefficient of variation $-\%$ 


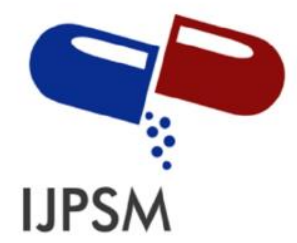

Yelti Mainita et al, Int. Journal of Pharmaceutical Sciences and Medicine (IJPSM), Vol.6 Issue. 3, March- 2021, pg. 50-61

ISSN: 2519-9889

Impact Factor: 3.426

CV) across five validation run lower limit of quantity (LLOQ), lower quality control (LQC), medium quality control (QMC), higher quality control (HQC), and upper limit of quantitation (ULOQ) less than 15. The accuracy specified at this level is within $\pm 13 \%$ in terms of relative error percentage [33].

A specific, sensitive and fast method based on high-performance liquid chromatography (HPLC) was developed for the simultaneous determination of telmisartan (TELM) and hydrochlorothiazide. (HCT) inhuman plasma using indapamide as an internal standard. The method utilizes protein deposition with acetonitrile only as sample preparation before RP-HPLC. The analyte was chromatographed on a shimpackaged cyanopropyl column in isocratic elution with methanol: $10 \mathrm{mM}$ ammonium acetate solution (pH 6.0) $(35: 65 \mathrm{v} / \mathrm{v})$ as the mobile phase at a flow rate of $1 \mathrm{~mL} / \mathrm{min}$ and a detection wavelength of $270 \mathrm{~nm}$. This method is validated in a concentration range of $1-10 \mu \mathrm{g} / \mathrm{mL}$ for TELM and $0.31-3.12 \mu \mathrm{g} / \mathrm{mL}$ for HCT in human plasma. The inter and intra-run precision of TELM and HCT is less than 3.60\%, and the accuracy is less than $1.868 \%$. Linearity, recovery, matrix effects, and stability were validated for TELM/HCT in human plasma [34].

A high-performance liquid chromatography method was developed, validated, and applied to determine hydrochlorothiazide in human plasma. The effects of mobile phase composition, buffer concentration, mobile phase $\mathrm{pH}$, and organic converter concentration on hydrochlorothiazide retention and internal standards were investigated. His method involved solid-phase extraction on the RP-select B cartridge followed by isocratic reverse phase chromatography on the Hibar Lichrospher 100 Column RP-8 with UV detection at $230 \mathrm{~nm}$. Recovery, selectivity, linearity, precision, and method accuracy were evaluated from spiny human plasma samples. The limit of quantification is $10 \mathrm{ng} / \mathrm{mL}$. Methods have been applied to monitor hydrochlorothiazide levels in patient samples [35].

\section{Conclusion}

The analysis method of hydrochlorothiazide as a raw material can be determined by high-performance liquid chromatography (HPLC), capillary zone electrophoretic (CZE), micellar electrokinetic capillary chromatography (MEKC), capillary electrophoresis, chemiluminescence, voltammetry, and quantitative point tests. Hydrochlorothiazide in a pharmaceutical dosage form can be determined by high-performance liquid chromatography, spectrophotometric, electroanalytic, thin layer chromatography (TLC) methods, voltammetry, and capillary zone electrophoresis. The hydrochlorothiazide in mixtures with other substances can be determined using voltammetry and high-performance liquid chromatography methods. Electrochemical and liquid chromatography methods can determine hydrochlorothiazides in biological fluids such as human urine and plasma.

\section{References}

[1]. Messerli FH, Makani H, Benjo A, Romero J, Alviar C, Bangalore S. Antihypertensive efficacy of hydrochlorothiazide as evaluated by ambulatory blood pressure monitoring: a meta-analysis of randomized trials. Journal of the American College of Cardiology. 2011 Feb 1;57(5):590-600.

[2]. Kementerian Kesehatan Republik Indonesia. Farmakope Indonesia Edisi VI. Jakarta: Kementerian Kesehatan Republik Indonesia; 2020.

[3]. Zendelovska D, Stafilov T, Miloševski P. Development of solid- phase extraction method and its application for determination of hydrochlorothiazide in human plasma using HPLC. Biomedical Chromatography. 2004 Mar;18(2):71-6.

[4]. Hillary S, Van den Bossche W. Simultaneous determination of hydrochlorothiazide and several angiotensin-IIreceptor antagonists by capillary electrophoresis. Journal of Pharmaceutical and biomedical analysis. 2003 Feb 26;31(2):329-39.

[5]. Hillary S, De Grauwe K, Van den Bossche W. Simultaneous determination of hydrochlorothiazide and several inhibitors of angiotensin-converting enzyme by capillary electrophoresis. Journal of Chromatography A. 2001 Jul 27;924(1-2):439-49. 


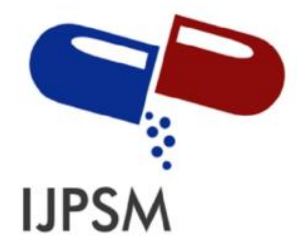

\section{Yelti Mainita et al, Int. Journal of Pharmaceutical Sciences and Medicine (IJPSM), Vol.6 Issue. 3, March- 2021, pg. 50-61}

ISSN: 2519-9889

Impact Factor: 3.426

[6]. Liu F, Xu Y, Gao S, Guo Q. Determination of hydrochlorothiazide in human plasma by liquid chromatography/tandem mass spectrometry. Journal of pharmaceutical and biomedical analysis. 2007 Sep 3;44(5):1187-91.

[7]. Pulgarın JM, Molina AA, Nieto GP. Determination of hydrochlorothiazide in pharmaceutical preparations by timeresolved chemiluminescence. Analytica chimica acta. 2004 Aug 2;518(1-2):37-43.

[8]. Bhagwate S, Gaikwad NJ. Stability indicating HPLC method for the determination of hydrochlorothiazide in pharmaceutical dosage form. Journal of Applied Pharmaceutical Science. 2013 Feb 1;3(2):88.

[9]. Alghamdi AF. Electrochemical oxidation behavior of hydrochlorothiazide on a glassy carbon electrode and its voltammetric determination in pharmaceutical formulations and biological fluids. journal of food and drug analysis. 2014 Sep 1;22(3):363-9.

[10]. Gotardo MA, Pezza L, Pezza HR. Determination of hydrochlorothiazide in pharmaceutical formulations by diffuse reflectance spectroscopy. Eclética Química. 2005;30(2):17-24.

[11]. Machini WB, David-Parra DN, Teixeira MF. Electrochemical investigation of the voltammetric determination of hydrochlorothiazide using a nickel hydroxide modified nickel electrode. Materials Science and Engineering: C. 2015 Dec 1;57:344-8.

[12]. Rajasekhar, D., Kumar, I.J. and Venkateswarlu, P., 2009. A high-performance liquid chromatography/negative ion electrospray tandem mass spectrometry method for the determination of hydrochlorothiazide in human plasma: Application to a comparative bioavailability study. European Journal of Mass Spectrometry, 15(6), pp.715-721.

[13]. Santos SX, Gomes Cavalheiro ÉT. Evaluation of the potentialities of a carbon nanotubes/silicone rubber composite electrode in the determination of hydrochlorothiazide. Analytical letters. 2012 Jul 15;45(11):1454-66.

[14]. AL-MOMANI IF. Determination of hydrochlorothiazide and enalapril maleate in tablet formulations by reversedphase HPLC. Turkish Journal of Chemistry. 2001 Feb 13;25(1):49-54.

[15]. Hegazy MA, Metwaly FH, Abdelkawy M, Abdelwahab NS. Spectrophotometric and chemometric determination of hydrochlorothiazide and spironolactone in binary mixture in the presence of their impurities and degradants. Drug testing and analysis. 2010 May;2(5):243-51.

[16]. Hudari FF, Souza JC, Zanoni MV. Adsorptive stripping voltammetry for simultaneous determination of hydrochlorothiazide and triamterene in hemodialysis samples using a multi-walled carbon nanotube-modified glassy carbon electrode. Talanta. 2018 Mar 1;179:652-7.

[17]. Naguib IA, Abdelaleem EA, Draz ME, Zaazaa HE. Linear support vector regression and partial least squares chemometric models for determination of Hydrochlorothiazide and Benazepril hydrochloride in presence of related impurities: a comparative study. Spectrochimica Acta Part A: Molecular and Biomolecular Spectroscopy. 2014 Sep 15;130:350-6.

[18]. Ganga R, Kaushik S, Sharma P. Spectrophotometric simultaneous determination of hydrochlorothiazide and telmisartan in combined dosage form. Journal of Applied Pharmaceutical Science. 2011 Mar 1;1(1):46.

[19]. Ganga R, Kaushik S, Sharma P. Spectrophotometric simultaneous determination of hydrochlorothiazide and telmisartan in combined dosage form. Journal of Applied Pharmaceutical Science. 2011 Mar 1;1(1):46.

[20]. Hegazy MA, Metwaly FH, Abdelkawy M, Abdelwahab NS. Validated chromatographic methods for determination of hydrochlorothiazide and spironolactone in pharmaceutical formulation in the presence of impurities and degradants. Journal of chromatographic science. 2011 Feb 1;49(2):129-35.

[21]. Eisele AP, Mansano GR, de Oliveira FM, Casarin J, Tarley CR, Sartori ER. Simultaneous determination of hydrochlorothiazide and valsartan in combined dosage forms: Electroanalytical performance of cathodically pretreated boron-doped diamond electrode. Journal of Electroanalytical Chemistry. 2014 Oct 15;732:46-52.

[22]. Parekh SA, Pudage A, Joshi SS, Vaidya VV, Gomes NA, Kamat SS. Simultaneous determination of hydrochlorothiazide, quinapril and quinaprilat in human plasma by liquid chromatography-tandem mass spectrometry. Journal of Chromatography B. 2008 Sep 15;873(1):59-69.

[23]. Obando MA, Estela JM, Cerdà V. Multi-syringe chromatography (MSC) system for the online solid-phase extraction and determination of hydrochlorothiazide and losartan potassium in superficial water, groundwater and wastewater outlet samples. Journal of pharmaceutical and biomedical analysis. 2008 Sep 10;48(1):212-7. 


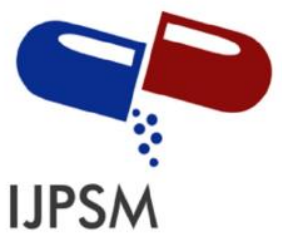

\section{Yelti Mainita et al, Int. Journal of Pharmaceutical Sciences and Medicine (IJPSM), Vol.6 Issue. 3, March- 2021, pg. 50-61}

[24]. Argekar AP, Sawant JG. A Gradient Reversed-Phase High Performance Liquid Chromatography Method for Simultaneous Determination of Hydrochlorothiazide (HCT) and Losartan Potassium (LOS) from Tablets.

[25]. Wang Q, Ding F, Li H, He P, Fang Y. Determination of hydrochlorothiazide and rutin in Chinese herb medicines and human urine by capillary zone electrophoresis with amperometric detection. Journal of pharmaceutical and biomedical analysis. 2003 Jan 1;30(5):1507-14.

[26]. Erk N. Three new spectrophotometric methods applied to the simultaneous determination of hydrochlorothiazide and irbesartan. Die Pharmazie-An International Journal of Pharmaceutical Sciences. 2003 Aug 1;58(8):543-8.

[27]. Hemke AT, Bhure MV, Chouhan KS, Gupta KR, Wadodkar SG. UV spectrophotometric determination of hydrochlorothiazide and olmesartan medoxomil in pharmaceutical formulation. E-Journal of Chemistry. 2010 Oct $1 ; 7$.

[28]. Santos MC, Tarley CR, Dall'Antonia LH, Sartori ER. Evaluation of boron-doped diamond electrode for simultaneous voltammetric determination of hydrochlorothiazide and losartan in pharmaceutical formulations. Sensors and Actuators B: Chemical. 2013 Nov 1;188:263-70.

[29]. Jafari-Kashi A, Shabani-Nooshabadi M. Simultaneous Determination of Hydrochlorothiazide and Folic Acid in Pharmaceutical and Biological Samples using a New Modified Nanostructure Sensor. Analytical \& Bioanalytical Electrochemistry. 2018 Aug 31;10(8):1016-30.

[30]. Galhardo KS, Dadamos TR, da Silva RJ, Machado SA. Development and validation of an advanced electrochemical sensor for the fast and cheap determination of hydrochlorothiazide in urine samples using the Monte-Carlo method for uncertainty evaluation. Talanta. 2020 Aug 1;215:120883.

[31]. Liu F, Xu Y, Gao S, Guo Q. Determination of hydrochlorothiazide in human plasma by liquid chromatography/tandem mass spectrometry. Journal of pharmaceutical and biomedical analysis. 2007 Sep 3;44(5):1187-91.

[32]. Liu D, Jiang J, Wang $\mathrm{P}$, Feng S, Hu P. Simultaneous quantitative determination of olmesartan and hydrochlorothiazide in human plasma and urine by liquid chromatography coupled to tandem mass spectrometry. Journal of Chromatography B. 2010 Mar 15;878(9-10):743-8.

[33]. Parekh SA, Pudage A, Joshi SS, Vaidya VV, Gomes NA, Kamat SS. Simultaneous determination of hydrochlorothiazide, quinapril and quinaprilat in human plasma by liquid chromatography-tandem mass spectrometry. Journal of Chromatography B. 2008 Sep 15;873(1):59-69.

[34]. Salama I. Simultaneous HPLC-UV analysis of telmisartan and hydrochlorothiazide in human plasma. Bulletin of Faculty of Pharmacy, Cairo University. 2011 Jun 1;49(1):19-24.

[35]. Zendelovska D, Stafilov T, Miloševski P. Development of solid- phase extraction method and its application for determination of hydrochlorothiazide in human plasma using HPLC. Biomedical Chromatography. 2004 Mar;18(2):71-6.

\section{A Brief Author Biography}

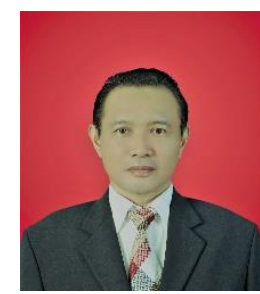

Prof. Dr. Harrizul Rivai, M.S., was born in Payakumbuh, West Sumatra, on 4 September 1953. His father is Rivai Said, and his mother is Saridahanum Syofyan. The Author obtained a Bachelor of Pharmacy from the Department of Pharmacy, Faculty of Mathematics and Natural Sciences, Padjajaran University, Bandung (1976), a Master of Science degree from the Bandung Institute of Technology (1984), and a Doctorate from the Department of Chemistry, Faculty of Mathematics and Natural Sciences, Andalas University, Padang (2011). Now the Author is a Professor and Researcher at the Faculty of Pharmacy, Andalas University, Padang. The Author also serves as Deputy Chair of Academic Affairs at the YPTIK Padang College of Pharmacy (STIFARM). The Author wrote the book "Principles of Chemical Examination" (Publisher UI-Press, 1995), translated the book "Pharmaceutical Statistics" (EGC Medical Book Publishers, 2010), and wrote "Chapter 4" in the book "Recent Research Advances in Biology Vol. 4" (International Book Publisher, India, and United Kingdom, 2020), and wrote the book "Chinese Petai (Leucaena leucocephala): Traditional Uses, Phytochemicals, and Pharmacological Activities" (Deepublish, Yogyakarta, 2021). The Author has also written articles in various international journals in various science fields, such as chemistry, biology, and pharmacy. 